\title{
LA RECREACIÓN Y EL TURISMO, UNA PROPUESTA DE FORMACIÓN DE LA UNIVERSIDAD PEDAGÓGICA NACIONAL*
}

\author{
TOURISM AND RECREATION: A PROPOSAL ON ACADEMIC TRAINING FROM THE NATIONAL \\ PEDAGOGICAL UNIVERSITY OF COLOMBIA
}

Astrid Bibiana Rodríguez Cortés**

Andrés Díaz Velasco***

Resumen

El siguiente artículo presenta la estructura del programa de la Licenciatura en Recreación y Turismo de la Facultad de Educación Física de la Universidad Pedagógica Nacional, propuesta que pretende seguir innovando y presentado nuevos retos de formación y proyección profesional a los egresados de dicha facultad.

Palabras clave: recreación, turismo, pedagogía

Abstract

This paper presents the program structure description of Tourism and Recreation degree from the Physical Education Faculty of National Pedagogical University of Colombia. A proposal that seeks to continue innovating and presenting new challenges related to the academic training and professional development opportunities to the bachelors from the faculty.

Keywords: recreation, tourism, pedagogy.

Fecha de recepción: 12 de diciembre de 2013

Fecha de aprobación: 10 de marzo de 2014

\footnotetext{
* Este artículo es tomado del documento enviado al Ministerio de Educación Nacional con el fin de lograr la Renovación de Registro Calificado y el cambio de titulación de la Licenciatura en Recreación. La propuesta en su totalidad fue elaborada por el grupo de docentes de planta y ocasionales del programa de dicha licenciatura. Las personas que presentan este texto retoman y organizan el documento a continuación, mas no son los únicos autores.

** Licenciada en Educación Física. Magíster en Educación Universidad Pedagógica Nacional. Coordinadora Licenciatura en Recreación y líder del proceso de Renovación de Registro de dicho programa. Facultad de Educación Física. Universidad Pedagógica Nacional. Miembro del grupo de investigación Lúdica, Cuerpo y Sociedad. Correos electrónicos: abrodriguez@pedagogica.edu.co astridbibianarc@yahoo.com

*** Licenciado en Educación Física, Universidad Pedagógica Nacional. Candidato a Magíster en Filosofía Universidad del Rosario, Bogotá Docente de la Licenciatura en Recreación y Turismo, Facultad de Educación Física, Universidad Pedagógica Nacional. Miembro del grupo de investigación Lúdica, Cuerpo y Sociedad. Correo electrónico: andresdiazvelasco@gmail.com
} 


\section{INTRODUCCIÓN}

La Licenciatura en Recreación y Turismo es una propuesta de formación que recoge la experiencia del programa Licenciatura en Recreación de la UPN de 2006, ampliando su horizonte formativo al campo (social y discursivo) del turismo, respondiendo, además, a dos procesos de autoevaluación del programa y a las proyecciones académicas de docentes y estudiantes. Todo ello en el marco de la renovación del registro calificado $^{1}$, coyuntura importante para fortalecer y permitir el desarrollo de los programas académicos y de las ofertas educativas. La propuesta de formación en recreación y turismo da respuesta, también, a la necesidad de formar agentes educativos para afrontar las necesidades lúdicas, socioculturales y ambientales de la nación colombiana, entendiendo que su quehacer profesional trasciende los límites del aula y contempla la construcción de propuestas político-educativas que adoptan nuevos campos sociales como ejes transversales de cualquier proceso de formación.

La propuesta de formación en recreación y turismo coincide con las perspectivas de análisis sobre el mundo contemporáneo que afirman la existencia de nuevas formas de construcción de subjetividad en las que los individuos se asumen, se relacionan y se conciben por medio de actos re-creativos, gracias a los cuales constituyen una sociedad radicalmente distinta a la heredada del siglo XIX². Se plantea que esta nueva sociedad presenta cambios a nivel tanto tecnológico como cultural y político, afectando las formas de relación e intercambio social de lo comunitario y, por tanto, alterando la dinámica misma de la educación dentro y fuera de la escuela. Si se sigue el planteamiento de Cornelio Águila, en su estudio crítico sobre el ocio y las sociedades posmodernas, según el cual los cambios contemporáneos tienen sus raíces en las "grandes revoluciones: la americana y la francesa, las cuales proporcionaron la estructura política e institucional, y

1 El registro calificado es la aprobación que reciben por parte del Ministerio de Educación Nacional los programas de educación superior que cumplen con los criterios nacionales de calidad. Luego de una primera aprobación, los programas que desean continuar funcionando deben renovar su registro siguiendo ciertas indicaciones legales.

2 La concepción original de estos procesos de subjetividad en los que los individuos se liberan a sí mismos de las sujeciones propias de las sociedades modernas fue elaborada por Foucault $(2005,2009)$, pero ha sido continuada, de un modo, a su vez renovado, entre otros, por Sloterdijk (2003). No se trata de otra cosa que de la ética como estética. la revolución industrial, que aportó la base económica para el desarrollo del industrialismo, del urbanismo y, finalmente, del capitalismo como sistema socioeconómico" (2007, p. 13), lo que queda por hacer, ante las condiciones actuales de la historia, es re-crear revoluciones en las que se potencie, como decía Deleuze (1995), "no ya la existencia como sujeto, sino como obra de arte" (p. 79) .

Por ello, esta propuesta académica demanda importantes retos y acciones en el contexto nacional e internacional: resulta indudable que la recreación y el turismo se ven permeados e interpelados por las formas contemporáneas de relación social. Urge así estudiar con una perspectiva crítica los fenómenos que configuran estas nuevas realidades $y$, sobre todo, desde una mirada pedagógica que posibilite, además, la creación de modos de ser y estar (o, en suma, de vivir) en el mundo. Pero, en la misma línea, apremia también reconocer que el conocimiento ya no es fijo ni estático y que, si se asume que vivimos en la sociedad del conocimiento -la cual demanda que los individuos se eduquen a lo largo de su vida y sean flexibles y adaptables a las condiciones del mercado-, ya no es únicamente la escuela la que educa, sino que existen diversos escenarios educativos que permiten comprender cómo el mundo se ha configurado distinto y, asimismo, cómo es posible ejercer una ciudadanía responsable (con la vida colectiva y el medio ambiente).

Se presenta, entonces, un proyecto pedagógico sobre el contexto de la recreación y el turismo, donde confluyen tres elementos: cultura, vida y sociopolítica. Estos han venido alimentando la propuesta de mundo y de realidad del Proyecto Académico Licenciatura en Recreación desde sus inicios, por lo que se reflejan en los contenidos curriculares tanto como en los desarrollos investigativos -los cuales articulan el quehacer del docente con la construcción del saber pedagógico, el desarrollo epistemológico interdisciplinar de la recreación y el turismo, y las relaciones teórico-prácticas del proceso formativo de licenciados. La estructura curricular se organiza facilitando convocar y actuar creativamente a profesores y estudiantes, en su relación con las disciplinas, los saberes y las prácticas, rompiendo así con la concepción tradicional de asignaturas o materias ais-

\footnotetext{
3 Se entiende por re-creación la acción de repensar y rehacer los procesos estructurados y modificarlos gracias al acto creativo e inspirador.
} 
ladas que fragmentan la formación. Además, tanto los ciclos como las áreas se encuentran ligadas por medio de estrategias como la sistematización y la vinculación de los proyectos de grado a las tres líneas de investigación de la licenciatura.

\section{EJES CONCEPTUALES}

El programa orienta el interrogante por el sentido de la recreación y del turismo en una dirección totalmente distinta a las pretensiones esencialistas. De ahí que considere a la recreación y al turismo como formas de interrogar y de abordar el mundo contemporáneo, y no como disciplinas del saber o meras actividades. La recreación y el turismo se definen, para el programa, como lugares de observación -perspectivas-; como formas de indagación que asumen tanto los procesos de diversión, de relajación, de vacaciones, como las dinámicas educativas, éticas, políticas y sociales. A continuación se desarrollan las nociones de recreación y turismo de acuerdo con los presupuestos conceptuales en que descansa el programa.

\section{El concepto de recreación}

El campo social de la recreación, en su extensión ilimitada, aflora como conjunto de relaciones actuales y potenciales de cuerpos y de sentidos. Se comprende así por qué la recreación está vinculada a la relajación y el entretenimiento, referida a prácticas como ver televisión, jugar o visitar museos -unas prácticas de "diversión para alivio del trabajo" (DRAE), para alegrarse o deleitarse-, e, igualmente, ligada al acto de volver a crear, de producir de nuevo una cosa -como empleo de las energías en la alteración de materiales, por ejemplo-. De allí también su relación con el campo artístico, el político/burocrático y el educativo, por nombrar unos pocos. En este orden de ideas, la recreación como campo social involucra la vastedad de agentes, grupos, instituciones, bienes, discursos, saberes y prácticas que la expresan: el uso de la palabra tanto como lo que le da su sentido.

Así las cosas, los licenciados de la Universidad Pedagógica Nacional son agentes sociales que interactúan o han de interactuar en este campo de forma intencionada, con una determinación, un proyecto, un modo de proceder producto del estudio cuidadoso, del pensamiento crítico y propositivo, de la reflexión y acción sistemáticas sobre el mismo campo. Intención atra- vesada por el carácter pedagógico que constituye su distinción en el campo en tanto que saber particular. Una interacción, pues, que interroga la relación enseñanza-aprendizaje, la construcción o producción del sujeto, los procesos de socialización y/o enculturación que la sociedad colombiana, en su realidad histórica, y la sociedad mundial, con sus problemáticas actuales, genera en el campo social recreativo.

Con base en lo anterior, puede comprenderse mejor por qué conceptualizar la recreación no solo es importante académicamente hablando (en cuanto universidad que ofrece un programa de profesionalización), sino que constituye un deber como agentes sociales gestores de cambio. Sin duda, al conceptualizar se explica el manejo o sentido de una palabra con el fin de evitar un equívoco y en relación con un problema o un conjunto de problemas que se pretenden solucionar o develar en la medida en que el concepto se desarrolla y materializa.

Se debe aclarar entonces: primero, hay por lo menos cuatro nociones formuladas en relación con el carácter pedagógico de la recreación: a) existe ampliamente la noción de que la recreación implica un exclusivo, y reducido, número de actividades que pedagógicamente hablando deben dirigirse con fines (valga decir) moralizantes respecto del buen uso del tiempo libre, esto es, del tiempo en el que no se realiza una actividad obligatoria; b) se considera también un tipo de educación recreativa por medio de la cual los saberes a enseñar (matemáticos, lingüísticos, morales, etc.) se presenten de forma amena y divertida; c) la recreación como un instrumento didáctico especialmente útil para instituciones sin esquemas formales de educación en las que se estimula y favorece el juego, sobre todo, infantil; y, d) en palabras de Guillermina Mesa y Harold Manzano (2009)

(...) La recreación como estrategia pedagógica es una actividad incluyente, que difiere de las actividades artísticas o deportivas en que no busca la finalidad de un producto (espectáculo) o la formación de un especialista. Aunque mantiene con estas y otras actividades socioculturales vínculos muy profundos, sus motivos sociales son muy distintos. Mientras las dos primeras se fundan en la diferenciación e individualización de los más hábiles y competentes, la segunda se define por la inclusión y la participación colaborativa de quienes la realizan sin que importe su condición y habilidades previas como requisito para realizarla (pág. 24-25). 
De estas cuatro, la última perspectiva es la más cercana a lo que ha venido planteando y poniendo en acción la Universidad Pedagógica Nacional; no obstante, con un factor diferenciador: se enfatiza sobre el acto creativo (y la dimensión temporal de la existencia) en función de la promoción de transformaciones sociales (y no solamente el reconocimiento de su posibilidad). Debe aclararse que no se trata, propiamente, de pretender direccionar la sociedad con un rumbo particular; los cambios sociales pueden tomar direcciones inesperadas e impensadas. El propósito es más bien tanto contribuir al posicionamiento de los sujetos en su momento histórico y su ubicación geográfica (conciencia históricogeográfica en el globo), como potenciar o impulsar su capacidad de agenciamiento en concordancia con su capacidad creativa. Evoca así la recreación, el replanteamiento de las estructuras y la inherencia de la creatividad en el ser humano.

De este modo, la definición de recreación en la UPN es la siguiente: la recreación es una mediación creativa con intencionalidad pedagógica que tiene como propósito aportar a la construcción del tejido sociocultural potenciando la imaginación y los lenguajes lúdicos que interpelan los discursos hegemónicos frente al trabajo, el tiempo libre y el ocio, para agenciar otros mundos posibles alternativos, alterativos e incluyentes.

En primer lugar debe precisarse el sentido de los términos empleados. Por mediación se apela a una lógica que no es la de los medios y los fines; cuando domina esta última perspectiva, el propósito de la acción se encuentra predeterminado y los medios se valoran según permitan o impidan el logro de dichos objetivos. Esta lógica eficientista deja de lado todos aquellos aspectos que reelaboran los fines, que redefinen los medios y que parten del conflicto, de los vacíos y de las incertidumbres para producir movimiento.

La mediación creativa no evade la intencionalidad, pero hace suyas todas aquellas circunstancias no previstas, esto es, hace suyos los agenciamientos. Las mediaciones no controlan los resultados y permiten las experimentaciones, las vacilaciones y los re-comienzos, de ahí que se enfatice en la posibilidad de interpelar (de interrogar las preguntas y las respuestas) los discursos y dispositivos hegemónicos, esto es, todas aquellas formas de percibir, sentir, recordar y proyectar que repro- ducen el orden social con sus formas de exclusión y de explotación.

La recreación se ubica desde una perspectiva crítica y propositiva que hace posible otros modos de ser, de imaginar y de construir-se, esto es, de ser-con-otros; modos capaces de alterar las dinámicas que producen y se benefician de las desigualdades. Esta alteración requiere de espacios capaces de imaginar y provocar dinámicas no jerárquicas (alternativas) de estar juntos (mundos incluyentes). Con estos elementos, se delinea el modo de interrogar y de abordar los fenómenos recreativos, el querer decir del programa.

\section{El concepto de turismo}

Sustancialmente, las miradas crítico-sociales sobre el turismo dan cuenta de una serie de problemáticas que el enfoque comercial, si bien no obvia, pareciera evitar a toda costa, refiriéndolos a condiciones históricas y procesos que considera inevitables por los que el desarrollo económico no puede detenerse (casos como la interacción multicultural, la construcción de infraestructura hotelera en zonas biodiversas y la promoción de visitantes en masa).

En este sentido, y entendiendo el turismo como un fenómeno que afecta a los seres humanos en sus desarrollos identitarios locales, se comprende la importancia de que existan procesos de formación centrados en que los lugareños defiendan su territorialidad, entendida ella como sus tradiciones, costumbres, hábitos y formas de vivir, lo que comporta, en definitiva, la creación de un ambiente de respeto y valor por su cultura para afrontar los fuertes problemas de colonización y aculturización. Asimismo, hacer énfasis en el cuidado ambiental (tarea que actualmente no es exclusiva de una sola área académica), representa un caso puntual debido a las relaciones que se establecen con la tierra, no solo en el sentido del sistema económico imperante, sino además respecto al reconocimiento de los modos en que cada zona los afronta. Sin lugar a dudas, la afectación que hace el turismo al ambiente es ampliamente conocido, así que se requiere formar y pensar propuestas donde el ambiente no sufra drásticamente al paso de los turistas y mostrar los beneficios que ello puede acarrear en el futuro del desarrollo de las comunidades anfitrionas. 
Ahora bien, para la construcción de una propuesta educativa en turismo, se han tenido en cuenta los avances en la educación para el tiempo libre y la pedagogía del ocio, la ciudad educadora y la pedagogía crítica y popular. De un lado, es propósito de la licenciatura seguir ahondando en el cuestionamiento a la segmentación del tiempo vital, dentro de la cual se han generalizado enfermedades relacionadas con el aumento de las velocidades, las responsabilidades productivas y el alejamiento de sí mismo. Por tanto, en contra del encaminamiento a hacer de nuestros jóvenes más productivos, eficientes, proactivos (o ultra-activos), se suscita a pensar que el sistema educativo se encargue de educar para el ocio a los niños, jóvenes y adultos; y más allá de los análisis nefastos que se pueden hacer relacionados con el vicio y la improductividad, de lo que se trata es de reconocer la validez del cuidado de sí (el cuidado del cuerpo), de sus espacios, su tiempo, el tiempo para sí y el estarjuntos (Han, 2012). Estudios como el de Igarza (2009) han mostrado que el ocio y el tiempo libre no necesariamente implican un no-hacer-nada y que, además, en medio de las ocupaciones obligatorias, existe la posibilidad de emprender un ocio intersticial liberador.

De este modo, la educación del tiempo libre y el ocio es una perspectiva que pretende que los sujetos reconozcan la importancia "de lo lúdico, la plenitud de lo artístico, la vivencia de lo bello y, en definitiva, la felicidad que puede sentir la persona humana ante un bienestar desinteresado" (Cuenca, 2004). Con esta pedagogía del ocio en línea turística, entonces, se busca que las personas puedan mejorar su calidad de vida, a partir de sus propias motivaciones y deseos, llegando a experiencias sinceras de libertad y desarrollo personal.

\section{OBJETOS DE ANÁLISIS TRANSVERSALES}

Como objetos de análisis, es decir, más que cosas cuyo comportamiento se espera entender para lograr su predicción y control, los conceptos transversales que concentran el desarrollo teórico del programa y orientan las relaciones entre docentes y estudiantes, son ámbitos problematizadores en los que se encamina la investigación y en torno de los cuales se despliega el quehacer epistémico de los licenciados en recreación y turismo. Estos conceptos sirven como ejes base del programa; de su articulación, de sus tensiones y rupturas, se deriva el campo cambiante en el que la construcción de saberes recreo-turísticos despliega su sentido. Los cuatro objetos de análisis son: la territorialidad, en cuanto apropiación simbólica del espacio por medio de técnicas corporales (en términos de Marcel Mauss); la temporalidad, como condición esencial de la existencia en tanto intensidad viva; la experiencialidad, entendida la experiencia como productora de subjetividad; y, finalmente, el ambiente, conforme producto del habitar creativo (tal como lo concibió Heidegger).

A continuación se presentan las definiciones operativas que se han construido para/desde la Licenciatura en Recreación y Turismo:

Territorialidad: el territorio evoca las diversas formas como los seres se hacen presentes en sus concretas formas de vivir. Por ejemplo, los lugares sagrados, que tienden a definirse por la presencia de lo divino, $y$ los festivos, que lo hacen generalmente por la presencia de la carne; tal como pasa con los lugares íntimos y públicos, a los que les corresponden unas prácticas particulares de acuerdo con la cultura; o la geografía, que ha sido signada por el miedo, así como aquellos espacios señalados por el deseo o por el afán, todos definiéndose por aquello que se hace presente, así como por lo que debe permanecer ausente. El territorio se construye, pues, en y a partir de la relación o interacción entre cuerpos (aun cuando éstos no se encuentren materialmente uno frente al otro, tal como lo ha posibilitado la introducción de las tecnologías de la comunicación).

Temporalidad: se acoge una noción existencial del tiempo en contraste con las determinaciones contingentes del mismo. Esto es, no se trata solo de la cronología, o del modo como cada sociedad organiza, sistematiza, administra, produce y controla el tiempo; sino de la forma como esos tiempos y ritmos adquieren intensidades en relación con la vida misma de los sujetos. La temporalidad hace referencia a ese tiempo pasando que cada uno es hasta que deja de ser, es decir, hasta la muerte (Heidegger); pero no solo eso, también refiere al modo como cada cual vivencia ese tiempo o, mejor, como cada quien lo siente (se sabe, por ejemplo, que en ocasiones como caminar hacia el cadalso, un minuto de espera se vive como toda una vida). Sin duda, la temporalidad depende de la cultura en que 
tales intensidades se advierten y, por lo mismo, varía históricamente. Ha de entenderse, entonces, cómo en el transcurrir la temporalidad se reescribe o se refunda.

Experiencialidad: esta noción alude al modo como lo vivido se recrea en emociones e ideas conforme la efectuación corporal de los acontecimientos (Deleuze, 1994). La experiencia es un proceso totalmente empírico (es decir, no trascendente) que da cuenta del hecho de que los cuerpos sufren afecciones por el constante contacto de todo aquello con lo que entran en relación, produciéndose con ello no solo diversas formas de subjetividad sino además distintas culturas o formas de vida colectiva (Díaz, 2007). En suma, el sujeto es experiencias; pero no en el sentido absoluto del sujeto dado, tal como lo entendía Hegel, sino -parafraseando a Foucault (2005)- en cuanto producto de la correlación, dentro de una cultura, entre campos del saber, tipos de normatividad y formas de relación con uno mismo.

Se afirma con esto que los saberes y prácticas de la recreación y del turismo se concretan en experiencias alterativas capaces de provocar otros modos de vivir-se. Se abre, pues, la entrada a un orden ficcional (Deleuze y Guattari, 1995) como esfera que articula las realidades del deseo, específicamente a través de los imaginarios, con el devenir previsto por las acciones educativas. Las ficciones útiles, en el sentido nietzscheano del término, pueden develar las realidades presentes -que son sin embargo ocultadas en el transcurrir cotidiano- en la producción de lo posible.

Ambiente: da cuenta de la interacción entre organismos y medios o, parafraseando a la Unesco, de un macrosistema formado por varios subsistemas. En tal sentido, el ambiente comprende un flujo continuo de energía y materia en el que se complementan, de manera holística, los sistemas humanos (económico, social, político, cultural y tecnológico) y los sistemas naturales (fauna, flora, hidrósfera, geósfera, atmósfera). Por lo que, como lo plantean Toro y otros (2009) "hombre-naturaleza se recrean y evolucionan continuamente en una sola unidad sistémica" (p. 2). Esta mirada particular del concepto ha modificado, sin duda, la concepción sobre el papel del hombre en el medio natural y ha puesto de manifiesto su grado de responsabilidad en las transformaciones del mismo.

\section{PERFIL PROFESIONAL}

El licenciado en recreación y turismo tiene las condiciones para:

- Participar en procesos investigativos que posibiliten el conocimiento, cuestionamiento y reflexión de saberes recreativos y turísticos, respecto a los usos y concepciones de los territorios y del tiempo que se refieren a los encuentros con el otro.

- Diseñar, dirigir y ejecutar proyectos recreativos y turísticos en los distintos sectores y niveles del sistema educativo.

- Crear, asesorar o promover organizaciones mediante las cuales se pueda llevar a cabo el proyecto cultural de la recreación y el turismo desde una perspectiva crítico-propositiva.

- Elaborar e implementar estrategias y acciones que demande el campo de la recreación y del turismo en el sector público o privado, promoviendo lecturas alternativas, alterativas e incluyentes de la vida cotidiana.

\section{PROPÓSITOS DE FORMACIÓN}

Son propósitos de formación de la Licenciatura en Recreación y Turismo los siguientes:

- Generar, socializar y recontextualizar conocimiento relacionado con la recreación y el turismo.

- Promover contextos recreativos y turísticos constructores de bienestar humano y ecológico en aras de una armónica calidad de vida.

- Integrar visiones de mundo que faciliten la interacción creativa y gesten en sí mismas cambios de acción en lo cultural, promoviendo el reconocimiento de procesos de creación colectiva que se despliegan a través de la educación.

- Formar licenciados en recreación y turismo con profundos conocimientos en los procesos socioeducativos, específicamente en relación con las dinámicas sociales de construcción del tiempo (respecto a la forma como se le concibe y administra) y de los territorios (en relación con el modo como éste articula el contacto con la otredad). 
- Contribuir en el fortalecimiento del proyecto cultural de la nación, con el fin de viabilizar procesos de convivencia, equidad y paz desde el saber recreativo y turístico.

- Potenciar el tejido sociopolítico de la nación con el fin de fortalecer procesos de identidad a partir del quehacer recreativo y turístico, en relación con las dinámicas culturales que se ponen en juego a través de los fenómenos globales en relación con la gestión del tiempo y del territorio, así como las dinámicas de control que se despliegan a través del entretenimiento y los fenómenos de ocio.

\section{LINEAMIENTOS PEDAGÓGICOS Y DIDÁCTICOS}

De acuerdo con el fundamental papel de la Universidad Pedagógica Nacional respecto a la formación de maestros -y, para este caso, específicamente la formación de licenciados en recreación y turismo-, es su deber brindar al país propuestas innovadoras y provocadoras para los contextos educativos contemporáneos, los cuales han de asumir con miradas renovadas las problemáticas de la sociedad colombiana actual. En consecuencia, la Licenciatura en Recreación y Turismo asume, como se ha sugerido hasta ahora, la formación de maestros críticos, creativos y posibilitadores de experiencias transformadoras y alternativas, conscientes de que el hecho social educativo es un extenso y complejo campo de estudio por el cual es posible ampliar el espectro práctico de la recreación, el ocio y el tiempo libre.

Así, la Licenciatura en Recreación y Turismo organiza sus contenidos curriculares, asumiendo la directriz de la Universidad Pedagógica Nacional del acuerdo 035 de 2006, en el cual se detallan los siguientes lineamientos para los programas de pregrado: a) fases de estudio, b) ambientes de formación, c) espacios académicos, d) núcleos integradores de problemas y e) la práctica pedagógica. A continuación se desarrollan dichos aspectos.

\section{Fases de estudio}

Este currículo se concibe como una propuesta abierta, flexible, pero no por ello menos compleja. Está compuesta por dos grandes fases en la formación: fundamentación y profundización. Esta última, dividida a su vez en dos ciclos (I y II).
La fase de fundamentación tiene como fin que los estudiantes se apropien críticamente de los objetos de análisis transversales que propone el programa, así como de los fundamentos epistemológicos, pedagógicos y metodológicos de la recreación y el turismo. Igualmente, en esta fase se propende a una crítica rigurosa a las implicaciones sociales del ser maestro en la sociedad colombiana.

La fase de profundización se orienta hacia una formación crítica del saber disciplinar, interpelando los discursos vigentes y promoviendo la producción académica de los estudiantes y maestros de acuerdo con las líneas de investigación trazadas. En esta fase, el estudiante hace proyecciones sobre sus intereses y necesidades de aprendizaje, permitiendo a partir de su trabajo de investigación y práctica docente, hacer un aporte a la cultura y la sociedad.

\section{Ambientes de formación}

Son los ámbitos de encuentro interdisciplinario que permiten identificar las problemáticas culturales y sociales del campo de la educación y de los saberes disciplinares. En ellos se construyen miradas amplias de análisis, las cuales potencian la comprensión del mundo (cambiante), donde el futuro maestro debe aportar con su conocimiento a la solución de problemas contemporáneos. El programa se organiza en torno a los siguientes ámbitos:

- Ambiente de formación pedagógica y didáctica: es aquí donde se producen relaciones y discusiones en torno al papel de la pedagogía y la didáctica como objetos fundantes de la formación del maestro. Asimismo, se ejerce una relación con el saber disciplinar, en este ámbito se proyectan las posturas críticas con miras a mejorar las condiciones y calidad de vida de los sujetos por medio de la educación y la pedagogía, generando propuestas creativas.

- Ambiente de formación disciplinar: comprende las discusiones que sobre el saber de la recreación y el turismo se realizan en la actualidad; permite, además, comprender la proyección académica e investigativa de cada campo. Particularmente importantes resultan aquí los objetos de análisis: temporalidad, territorio, ambiente y experiencia, ya que permiten hacer una mirada a las tensiones propias de estos campos. 
- Ambiente de formación ética y cultural: aquí se lleva a cabo una comprensión del fenómeno de la recreación y el turismo como campos sociales con problemáticas convivenciales conjugadas en la realidad nacional e internacional. Este ambiente permite reconstruir las visiones de mundo de una manera más equilibrada social y políticamente hablando. Permite, además, interrogar por lo humano a partir del estudio de manifestaciones recreativas y turísticas alternativas.

Tabla 1. Ejes y ambientes de formación

\begin{tabular}{|c|c|c|}
\hline EJE DE ESTUDIO & EJE DE ESTUDIO & EJE DE ESTUDIO \\
\hline $\begin{array}{l}\text { AMBIENTE PEDAGó- } \\
\text { GICO-DIDÁCTICO }\end{array}$ & AMBIENTE DISCIPLINAR & $\begin{array}{l}\text { AMBIENTE ÉTICO-CULTU- } \\
\text { RAL O HUMANÍSTICA }\end{array}$ \\
\hline \multicolumn{3}{|c|}{ Ciclo de fundamentación } \\
\hline $\begin{array}{l}\text { Conocimiento de sí y } \\
\text { del ambiente social }\end{array}$ & Tiempo, territorio y ambiente & Sujeto, cultura y expresión \\
\hline \multicolumn{3}{|c|}{ Ciclo de profundización I } \\
\hline $\begin{array}{l}\text { Propuestas de pedagogía de } \\
\text { la recreación y el turismo }\end{array}$ & Tiempo, territorio y ambiente & Hegemonía, poder y resistencia \\
\hline \multicolumn{3}{|c|}{ Ciclo de profundización II } \\
\hline $\begin{array}{l}\text { Experiencias alterativas, } \\
\text { alternativas e incluyentes }\end{array}$ & $\begin{array}{l}\text { Diseño de propuestas en } \\
\text { recreación y turismo }\end{array}$ & $\begin{array}{c}\text { Fundamentación la propuesta } \\
\text { de recreación y turismo }\end{array}$ \\
\hline
\end{tabular}

\section{Espacios de provocación creativa (espacios académicos)}

Los espacios de encuentro académico fueron denominados en la Licenciatura en Recreación (2006) como espacios de provocación creativa, lo cual sugiere una serie de modificaciones con los espacios académicos convencionales; por ello, se sigue acogiendo esta propuesta que ha permitido reevaluar en varios aspectos lo que significa el encuentro de estudiantes y maestros en un espacio de formación. La característica más relevante de estos escenarios es el manejo de principios de formación de sujetos críticos, quienes a partir de la comprensión del hecho educativo pueden conducir relaciones menos jerárquicas y más concertadas en la relación maestro-estudiante, lo cual exige el planteamiento de metodologías que exploren el pensamiento creativo de ambos conforme prácticas de transformación y autorreflexión. Estos lineamientos permiten que la Licenciatura desarrolle los propósitos de formar sujetos con las siguientes particularidades:

Perspectiva crítica en la formación de Licenciados en Recreación y Turismo: la formación con perspectiva crítica implica hacer una apuesta por formar sujetos que se sensibilicen ante los problemas contemporáneos de la sociedad global, conscientes además de la importancia de la educación para una verdadera transformación social. Se conciben, entonces, sujetos capaces de proponer mejores sociedades, partiendo del reconocimiento del otro y de la acción tanto individual como colectiva, en cuanto posibilitadoras de cambios. Por ello, la propuesta formativa realiza constantemente procesos de interpelación, contradicción, reflexión o, en suma, 
de movilizaciones de pensamiento y acción. Se analizan las condiciones de vida actuales con base en la historia y de acuerdo con distintas configuraciones sociológicas y filosóficas. Se entiende, así mismo, que la formación y la educación no son construcciones unilaterales, sino al contrario que son procesos dialógicos (en el sentido propuesto por Freire), constructores de múltiple realidades, creadores de realidades distintas.

En la formación de pensamiento crítico se adoptan, pues, las siguientes consideraciones:

- El maestro es un intelectual (y no un simple hacedor de actividades) que con su saber pedagógico en materia de recreación y turismo propende a transformar la realidad social a través de movilizaciones pacíficas contextualizadas.

- La enseñanza en los campos recreativo y turístico no radica en la simple capacitación de mano de obra calificada, sino que se basa en la convicción de la capacidad alterativa. La enseñanza es un entramado que se establece entre los agentes que intervienen en ella y posee la fuerza de la problematización, el consenso y el disenso, la deliberación argumentada, la defensa del pensamiento (y sobre todo del pensar por sí mismo) y la construcción de conocimiento en distintos campos discursivos.

- La escuela, como foco de estudio, ha de ser resignificada con base en su tratamiento como territorio de acción colectiva, donde se producen transformaciones sociales y se acrecienta la posibilidad de interpelarse social y colectivamente. Escenario, pues, de formación para la felicidad y la diversidad de concepciones de mundo.

- Es necesario intervenir en los nuevos escenarios en los cuales está presente la pedagogía de la recreación y el turismo, debido a su importancia para la comprensión de las realidades sociales actuales (en lo que corresponde a las formas como la sociedad de consumo mercadea un tipo de recreación y turismo convirtiéndolos en discursos hegemónicos poco reflexionados).

- Es necesario, a su vez, permitir la exploración de soluciones a situaciones problematizadoras. Esto es, resulta imprescindible generar espacios de interrogación y proposición del presente y de las realidades personales del maestro y del estudiante para que se expresen y construyan conjuntamente.

Desarrollo del pensamiento creativo y potenciación de la creatividad: como ya se ha venido mostrando, el pensamiento crítico implica necesariamente el pensamiento creativo. Parafraseando a Deleuze y Guattari (2005), la crítica implica siempre una propuesta creativa precisamente sobre lo que se está criticando. Pero, también, ha de considerarse a la creatividad como un aspecto esencial e impulsor de la vida (en cuanto poiesis o producción). Por tanto, en la Licenciatura en Recreación y Turismo, se asume que los espacios de provocación creativa son escenarios en los que se desarrolla el pensamiento creativo -a través de los interrogantes y confrontaciones en el sentido en que "lejos de ser la antítesis de la creatividad, las restricciones sobre el pensamiento son las que [la] hacen posible" (Boden, 1994, p. 122)-, y se potencia la creatividad -como característica innata del «hombre» en tanto "la esencia humana de la naturaleza y la esencia natural del hombre se identifican en la naturaleza como producción" (Deleuze y Guattari, 1995, p. 14).

Así, pues, en relación con las variadas definiciones cognitivistas de la creatividad, en las que se le reconoce como un proceso complejo integrado y complementado con componentes emocionales, la licenciatura da lugar a la transgresión del orden sobre la confianza de que conocer, comprender, interrogar e interactuar propicia la innovación y el advenimiento de lo diferente. De este modo, el ser creativo no depende de un don especial, si no de la configuración de un contexto o escenario propicio donde se pueda desarrollar y potenciar conforme la intención de hacerlo.

Posibilitador de experiencias desde la imaginación, la fantasía, la ficción y la simulación: lo anterior confluye, entonces, en la configuración de espacios de provocación por medio de la interacción. Se proyecta a los estudiantes como gestores o posibilitadores de experiencias en el sentido de que estarán en la capacidad de proponer y construir -con conciencia e intención- ambientes (o ámbitos) en los que los sujetos, los artefactos, el tiempo y el espacio se relacionarán alterativa, alternativa e incluyentemente. Pondrán en ejercicio, pues, su imaginación (facultad creadora) en la confección de potentes simulaciones caracterizadas por altos niveles de fantasía (arte, mundos posibles) y útiles ficciones precursoras de lo imposible, de lo inexistente, de lo impensable. Los cuerpos, así, se subjetivarán o se producirán a sí mismos en libertad. 


\section{Núcleos integradores de problemas}

Estos núcleos sitúan a los estudiantes y docentes en un mapa de intencionalidad por el que los contenidos de los espacios de provocación creativa en cada semestre han de orientarse, conforme problemáticas contemporáneas que permiten la integración interdisciplinar de saberes en torno al campo de la recreación y el turismo como generadores de nuevos discursos y prácticas pedagógicas. Los núcleos integradores de problemas se encuentran en directa relación con los objetos transversales de análisis y los propósitos de formación del programa y están diseñados para favorecer el pensamiento sobre sí mismo de los estudiantes. Los núcleos de problematización son los siguientes.

Tabla 2. Núcleos de problematización

\begin{tabular}{|l|l|}
\hline \multicolumn{1}{|c|}{ CICLO DE FUNDAMENTACIÓN } \\
\hline PEMESTRE & NUCLEOS DE PROBLEMATIZACIÓN \\
\hline Segundo & $\begin{array}{l}\text { Conocimiento de sí. Biografía pedagógica, creativa, recreativa y del propio } \\
\text { desarrollo. }\end{array}$ \\
\hline Tercero & Contextualización de los sujetos. \\
\hline Cuarto & Adquisición de herramientas de análisis sociales y recreativos. \\
\hline Quinto & $\begin{array}{l}\text { Contextualización de la recreación y el turismo en los procesos de desarrollo } \\
\text { latinoamericano. }\end{array}$ \\
\hline & $\begin{array}{l}\text { Apropiación, problematización y proposición de alternativas en recreación y } \\
\text { turismo a partir de los desarrollos académicos. }\end{array}$ \\
\hline
\end{tabular}

\begin{tabular}{|l|l|}
\hline \multicolumn{2}{|c|}{ CICLO DE PROFUNDIZACIÓN } \\
\hline Sexto & NUCLEOS DE PROBLEMATIZACIóN \\
\hline Séptimo & $\begin{array}{l}\text { Tensiones de la pedagogía de la recreación y el turismo en distintos contex- } \\
\text { tos. }\end{array}$ \\
\hline Octavo & Formulación del proyecto de grado. \\
\hline Noveno & Consolidación del proyecto de grado. \\
\hline Décimo & Desarrollo del proyecto de grado. \\
\hline
\end{tabular}




\section{La práctica pedagógica}

Se asume la práctica pedagógica del programa en recreación y turismo retomando el artículo 11 del acuerdo 035 del 18 de agosto de 2006, el cual la define como:

El espacio de reflexión-acción e investigación en torno a la integración, innovación indagación y recontextualización de los saberes de orden cognitivo, ético, estético, pedagógico, didáctico y disciplinar en un contexto sociocultural específico, que presenta necesidades e intereses diversos, en función de la formación profesional del estudiante, su crecimiento personal y social.

Además de la función y objetivos consagrados por el acuerdo 035, se asignan los siguientes objetivos:

- Contextualizar los conocimientos y saberes aprehendidos en la universidad en espacios de carácter educativo formal y Educación para el trabajo y desarrollo humano.

- Confrontar saberes en el ejercicio de la docencia bajo la supervisión de un tutor.
- Acercar al estudiante a las características del rol profesional para el cual se está formando.

- Reflexionar de forma crítica y propositiva entorno al impacto educativo de la recreación en los diferentes contextos y escenarios donde interviene de forma pedagógica.

- Desarrollar los procesos de investigación formativa que se requieran en cada práctica educativa.

- Retroalimentar la propuesta formativa de la Licenciatura en Recreación.

En este sentido, para el programa la práctica es un espacio de confrontación, proposición y acercamiento constante al hecho educativo, concibiendo este último no solo en la educación formal, sino en los diversos contextos donde se produce. Por tanto, es misión del estudiante posicionar el saber recreativo y turístico en los diversos contextos de su acción docente, con perspectivas lúdicas y fortaleciendo el ocio como dimensión humana.

Tabla 3. Prácticas pedagógicas

\begin{tabular}{|c|c|c|c|}
\hline Semestres & $\begin{array}{l}\text { Denominación } \\
\text { de la práctica }\end{array}$ & $\begin{array}{l}\text { Procesos cognitivos, sociales } \\
\text { y pedagógicos a desarrollar }\end{array}$ & Estrategia \\
\hline $\mathrm{I}-\mathrm{V}$ & $\begin{array}{c}\text { Se encuentra en el } \\
\text { desarrollo de todos los } \\
\text { espacios académicos }\end{array}$ & $\begin{array}{l}\text { Adquiere habilidades de pen- } \\
\text { samiento investigativo: des- } \\
\text { cribe, sintetiza, analiza, con- } \\
\text { fronta, interpreta, propone. }\end{array}$ & $\begin{array}{l}\text { Las salidas pedagógicas programadas y } \\
\text { el contenido propio de cada uno de los } \\
\text { espacios académicos tienen como fin } \\
\text { enfatizar en el desarrollo de cada una } \\
\text { de estas habilidades cognitivas, socia- } \\
\text { les y pedagógicas, así como propiciar } \\
\text { espacios para el análisis, la confronta- } \\
\text { ción y la comparación de los diferen- } \\
\text { tes contextos pedagógicos y sociales. }\end{array}$ \\
\hline VI & $\begin{array}{l}\text { Práctica pedagó- } \\
\text { gica en recreación }\end{array}$ & $\begin{array}{l}\text { Esta busca que los estudiantes } \\
\text { generen estrategias pedagógi- } \\
\text { cas de la recreación en los dis- } \\
\text { tintos contextos educativos. }\end{array}$ & $\begin{array}{l}\text { Realizará aproximaciones a diversos } \\
\text { ámbitos educativos de educación for- } \\
\text { mal, no formal, o instituciones para } \\
\text { el desarrollo humano y el trabajo. }\end{array}$ \\
\hline VII & $\begin{array}{l}\text { Práctica pedagó- } \\
\text { gica en turismo }\end{array}$ & $\begin{array}{l}\text { Busca que los estudiantes puedan } \\
\text { hacer intervenciones de tipo curri- } \\
\text { cular sobre el turismo y su pro- } \\
\text { yección a la localidad y la ciudad. }\end{array}$ & $\begin{array}{l}\text { Realizará aproximaciones a diversos } \\
\text { ámbitos educativos de educación for- } \\
\text { mal, no formal, o instituciones para } \\
\text { el desarrollo humano y el trabajo. }\end{array}$ \\
\hline
\end{tabular}




\begin{tabular}{|c|c|c|c|}
\hline VIII & $\begin{array}{l}\text { Práctica pedagó- } \\
\text { gica empresarial en } \\
\text { recreación o turismo }\end{array}$ & $\begin{array}{l}\text { De acuerdo con el énfasis selec- } \\
\text { cionado por el estudiante, se hace } \\
\text { un acercamiento en el campo de } \\
\text { turismo o la recreación. Busca } \\
\text { generar estrategias pedagógicas } \\
\text { que permitan ver la importan- } \\
\text { cia de trabajar la recreación y el } \\
\text { turismo con sentido pedagógico } \\
\text { en los ambientes empresariales. }\end{array}$ & $\begin{array}{l}\text { Prácticas en empresas que permitan } \\
\text { la implementación de nuevas postu- } \\
\text { ras teóricas y prácticas de la recrea- } \\
\text { ción y la educación en el turismo. }\end{array}$ \\
\hline IX-X & $\begin{array}{c}\text { Práctica inves- } \\
\text { tigativa I y II }\end{array}$ & $\begin{array}{l}\text { Es un proceso de sistematización } \\
\text { y proposición de las proyeccio- } \\
\text { nes del estudiante como profesio- } \\
\text { nal. Busca afianzar elementos de } \\
\text { investigación formativa y su puesta } \\
\text { en práctica en ejercicios concretos } \\
\text { de producción de conocimiento. }\end{array}$ & $\begin{array}{l}\text { Se desarrolla junto con su trabajo de } \\
\text { grado. Esta práctica puede ser imple- } \\
\text { mentada por el estudiante de acuerdo } \\
\text { con sus necesidades de implementar } \\
\text { y finiquitar su propuesta pedagógica. }\end{array}$ \\
\hline
\end{tabular}

En cada uno de los espacios de práctica, el estudiante debe finalizar con un trabajo en el cual se sistematiza su quehacer docente y los propósitos cumplidos en ella. La sistematización de $\mathrm{V}$ semestre ha de contenerla según el lenguaje lúdico-recreativo elegido; las de VI y VII semestre se presentarán en cada semestre y se acomodarán como anexo del trabajo de grado a presentar en $\mathrm{X}$ semestre, $\mathrm{y}$, finalmente, en el trabajo de grado a sustentar se debe incluir, bien como un informe anexo o como parte del mismo trabajo, según lo acordado con el tutor respectivo y según la modalidad de graduación elegida. Esta sistematización es entregada a la institución como muestra de los logros cumplidos por el estudiante practicante y asimismo se hace una presentación y confrontación con sus compañeros de práctica, ella busca dar a conocer la experiencia y vivencia del estudiante practicante y la retroalimentación que hacen sus compañeros y profesores al proceso.

Desde esta perspectiva, la sistematización de la práctica pedagógica es una estrategia importante y una actividad fundamental para el fortalecimiento de la formación investigativa (por el necesario registro que ha de hacerse en diarios de campo, bitácoras, hojas de registro y fichas de observación, entre otros), así como de la construcción de saber pedagógico conjunto y constante con sus tutores y compañeros. Las particularidades de la práctica pedagógica se encuentran en el Reglamento de Práctica Pedagógica, que ha sido construido por maestros y estudiantes y tiene como fin regular y proponer modalidades de práctica de acuerdo con el contexto en el cual se desarrollan la recreación y el turismo actualmente.

\section{LUGARES DE DESEMPEÑO LABORAL}

El licenciado en recreación y turismo puede estar vinculado con procesos pedagógicos y administrativos con diversos grupos poblacionales en contextos como:

- Organizaciones culturales a nivel nacional e internacional.

- Sistema educativo nacional.

- Entidades promotoras del campo de la recreación y el turismo.

- Organizaciones no gubernamentales que trabajen por el cuidado ambiental, turístico y recreativo.

- Instituciones que promuevan el aprovechamiento del tiempo libre.

- Desarrollo de programas administrativos y pedagógicos en el campo del turismo, la recreación, el ocio y el tiempo libre.

- Instituciones de educación superior y centros de investigación en campos de educación, recreación, ocio y turismo. 
Los retos que implica para la UPN liderar una formación en el campo de la recreación y el turismo siguen siendo un camino por recorrer; presentar nuevas perspectivas a estos campos que han estado liderados por la instrumentalización y la administración son asuntos impor- tantes que la formación pedagógica no puede desconocer y debe atender. Sin embargo, la Facultad de Educación Física sigue liderando nuevas maneras de pensar la educación física, el deporte y la recreación para el país.

\section{REFERENCIAS BIBLIOGRÁFICAS}

Águila, C. (2007). Sobre el ocio y la posmodernidad: un análisis sociocrítico. Sevilla: Wanceulen.

Boden, M. (1994). La mente creativa. Mitos y mecanismos. Barcelona: Gedisa.

Cuenca, M. (2004). Pedagogía del ocio: modelos y propuestas. España: Universidad de Deusto.

Deleuze, G. (1994). Lógica del sentido. España: Editorial Planeta.

Deleuze,G. (1995). Conversaciones. España: Pre-textos.

Deleuze, G. y Guattari F. (1995). El anti-Edipo. Capitalismo y esquizofrenia. España: Ediciones Paidós Ibérica.

Deleuze, G. y Guattari F. (2005). ¿Qué es la filosofía? Barcelona: Editorial Anagrama.

Díaz Velasco, A. (2007). ¿Qué nos insinúa la experiencia corporal? Revista Lúdica Pedagógica, 2(12).

Foucault M. (2005). El sujeto y el poder. Pensamiento y experimentación. Bogotá: Carpe Diem y Tejer.

Foucault, M. (2009). El yo minimalista y otras conversaciones. Buenos Aires: La Marca Editora.

Han, B. (2012). La sociedad del cansancio. Barcelona: Herder.

Igarza, R. (2009). Burbujas de ocio. Buenos Aires: La Crujía.

Mesa, G. y Manzano, H. (2009). La recreación dirigida: un laboratorio pedagógico para la contemplación activa y creativa de la televisión. Colombia: Comisión Nacional de Televisión y Universidad del Valle. Recuperado de http://www.cntv.org.co/cntv_bop/estudios/ academicas/univalle1.pdf

Sloterdijk, P. (2003). Experimentos con uno mismo. Una conversación con Carlos Oliveira. España: Pre-Textos.

Toro, J., Osorio L. y Castiblanco, C. (2009). Seminario escuela para la participación y la gestión ambiental territorial y Local. Bogotá: Universidad Nacional de Colombia. 